\title{
Bone healing after biodegradable mini-plate fixation ${ }^{1}$
}

\author{
Onur Atali', Gokhan Gocmen" ${ }^{\mathrm{II}}$, Sertac Aktop ${ }^{\mathrm{III}}$, Esin Ak ${ }^{\mathrm{IV}}$, Selcuk Basa ${ }^{\mathrm{V}}$, Sule Cetinel ${ }^{\mathrm{VI}}$
}

DOI: http://dx.doi.org/10.1590/S0102-865020160060000001

IPhD, DDS, Department of Oral \& Maxillofacial Surgery, Faculty of Dentistry, Marmara University, Istanbul, Turkey. Scientific, intellectual, conception and design of the study; acquisition, analysis and interpretation of data; technical procedures; statistical analysis; manuscript preparation and writing; critical revision.

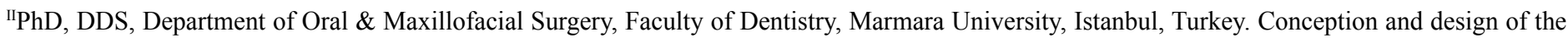
study, technical procedures, statistical analysis, manuscript writing, critical revision.

IIIPhD, DDS, Department of Oral \& Maxillofacial Surgery, Faculty of Dentistry, Marmara University, Istanbul, Turkey. Acquisition of data, statistical analysis, manuscript writing, critical revision.

${ }^{\mathrm{IV}} \mathrm{PhD}$, DDS, Department of Histology \& Embryology, Faculty of Dentistry, Marmara University, Istanbul, Turkey. Histological examinations, manuscript preparation, critical revision.

vProfessor, Department of Oral \& Maxillofacial Surgery, Faculty of Dentistry, Marmara University, Istanbul, Turkey. Scientific, intellectual, conception and design of the study; analysis and interpretation of data, final approval.

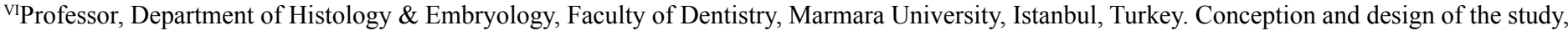
technical procedures, histological examinations, final approval.

\section{ABSTRACT}

PURPOSE: To compare bone healing in mandibular vertical body osteotomies (MVBO) after fixation with a resorbable 2.0mm-profile fixation system in the first and third postoperative months in rabbits.

METHODS: Twenty hemimandibles of ten rabbits were divided into two groups according to duration of resorbable fixation- one or three months. The MVBOs were performed and one four-hole, resorbable, $2.0 \mathrm{~mm}$ mini-plate fixation system was used on each side. The computed tomography (CT) scans, scanning electron microscopy (SEM), and histomorphometric outcomes of groups I and II were compared.

RESULTS: Significant differences were found between the one- and three- month assessments in terms of newly formed bone ratio values $(\mathrm{p}<0.05)$. There was more new bone formation at the third month on both the CT and histomorphometric examinations. A better adaptation of the bone tissues to the resorbable mini-plate and screws was observed on SEM at three months.

CONCLUSION: The resorbable mini-plates provided a fixation stable enough to allow immediate oral alimentation and callus formation in both groups.

Key words: Absorbable Implants. Tomography, X-Ray Computed. Mandibular Fractures. Osteotomy. Microscopy, Electron Scanning. Rabbits. 


\section{Introduction}

Resorbable fixation systems are biologically inert, which offers great advantages while avoiding the need to remove the implanted material. The first use of these materials was in pediatric craniofacial surgery, which requires less rigidity ${ }^{1}$. Favorable fracture healing has also been observed in osteosynthesis with biodegradable systems in adults ${ }^{2-5}$. They have been used in midfacial fractures as well as maxillary and mandibular osteotomies in orthognathic surgery ${ }^{6-8}$.

The use of resorbable fixation systems for osteosynthesis is currently a controversial issue in the literature. Various studies have been published regarding the disadvantages of biodegradable osteosynthesis materials, varying from less stabilization to more difficulty in handling ${ }^{4,9}$. However, many reports have shown that resorbable osteosynthesis yields comparable results in terms of stability and relapse $\mathrm{e}^{10-13}$

Osteosynthesis with resorbable mini-plate systems is affected by several factors, including osteotomy technique, type of fixation, amount of bony contact, subjected forces to the osteotomy line, mechanical strength of plates, and unique characteristics of the healing process in the bone that differ with time in individual patients. In the current literature, biomechanical tests (servohydraulic tests and finite element analyses), clinical outcomes (e.g., relapse, inflammation, function), and radiographic assessments (pre- and postoperative computed tomography (CT) or X-rays) are common methods of assessing resorbable miniplate osteosynthesis. However, bone healing in the osteotomy gap must be highlighted at the microscopic level, due to its association with the biodegradation phenomenon in this region; as such, time gains importance in this regard.

To the best of our knowledge, while the effects of different types of factors on postoperative osteosynthesis have been well studied, there have been no reports regarding the relationships among bone healing process, resorbable plate biodegradation, and osteosynthesis at particular time-points ${ }^{14,15}$. Therefore, the aim of the present study was to compare bone healing in mandibular vertical body osteotomy (MVBO) after fixation with a resorbable $2.0 \mathrm{~mm}$ fixation system in the first and third postoperative months in rabbits.

\section{Methods}

The study protocol was reviewed and approved by the Institutional Animal Care and Use Committee of the University of Marmara (approval number: 44.2009) in accordance with the Council for International Organization of Medical Sciences (CIOMS).

Ten healthy female adult New Zealand rabbits, 6-8 months of age and weighing $3-3.5 \mathrm{~kg}$, were used as subjects.

The animals were divided into two groups; all 20 hemimandibles of the ten rabbits were used. In Group I $(n=10)$, histomorphometric and scanning electron microscopy (SEM) analyses of the samples and CT scans were obtained in the first postoperative month. The same evaluations were made for Group II $(n=10)$ in the third postoperative month.

\section{Surgical procedure}

The biodegradable compact plating system CPS ${ }^{\circledR}$ (Inion Ltd, Tampere, Finland) was used. This system is composed of L-lactide, D,L-lactide, polyglycolide, and trimethylene carbonate and $2.0 \mathrm{~mm}$-profile four-hole straight mini-plates and $7 \mathrm{~mm}$-long screws .

The animals were sedated with $35 \mathrm{mg} / \mathrm{kg}$ ketamine i.m. (Ketalar; JHP Pharmaceuticals ${ }^{\circledR}$, Rochester, MI) and 10 $\mathrm{mg} / \mathrm{kg}$ xylazine (Rompun; Bayer ${ }^{\circledR}$, Leverkusen, Germany). A submandibular incision $(2 \mathrm{~cm})$ and a blunt dissection were performed to reach both bodies of the right and left mandibles. After completion of the cuts, the biodegradable mini-plates/screws were placed using drilling and tapping procedures. In each animal, a four-hole straight mini-plate and four screws were placed in a manner perpendicular to the upcoming osteotomies on the lateral aspects of the right and left mandibular bodies.

All of the animals were fed their normal diets beginning on the second postoperative day. The rabbits were kept in separate cages and inspected by a veterinarian. Each animal received $40,000 \mathrm{IU} / \mathrm{kg}$ penicillin $\mathrm{G}$ procaine (Eczacıbaş1 ${ }^{\circledR}$, Istanbul, Turkey) and $2 \mathrm{mg} / \mathrm{kg}$ ketoprofen (Profenid; Eczacıbaş ${ }^{\circledR}$, Istanbul, Turkey) once a day for five days. After the rabbits were euthanized, the mandibles were extracted with care and prepared for CT scan, light microscopy (LM), and SEM analysis (Figure 1). The bony stumps carrying the mini-plates/screws were prepared for SEM analysis, whereas the lingual segments with the osteotomy lines were prepared for LM. 


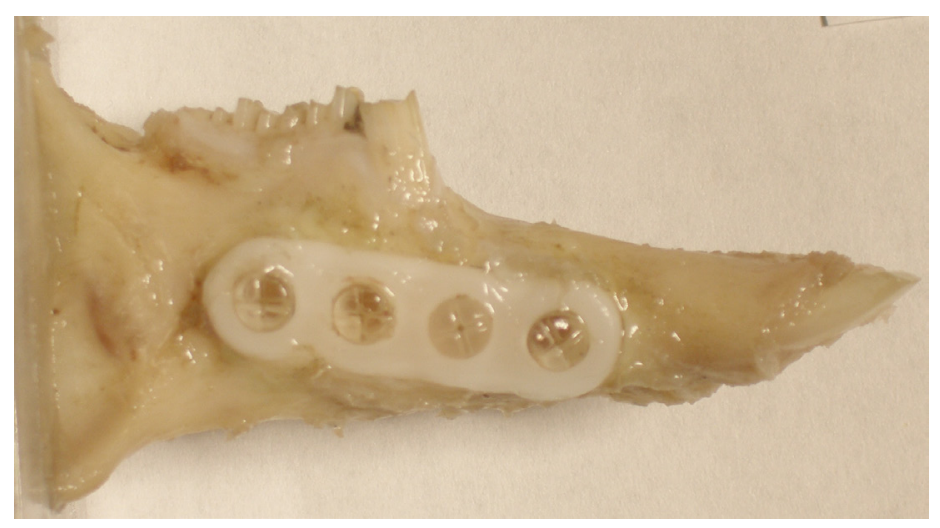

FIGURE 1 - Hemi-mandible and resorbable mini-plate/screw system after cleaning off the soft tissues.

\section{CT examinations}

Prior to obtaining histological samples from the mandibular bodies, CT scans of $0.5 \mathrm{~mm}$ sections were obtained in DICOM format. The data of the two sides from each rabbit were evaluated separately. Quantitative assessment and newly formed bone volume were quantified by CT density changes (Hounsfield units [HU]) in the osteotomy gap. The denser the tissue, the higher is the CT number, which ranges from $-1000 \mathrm{HU}$ (air) to $1000 \mathrm{HU}$ (dense bone) (16). The average HUs of the cortical (1000 HU) and spongious (770 HU) parts of the mandibular body of each experimental model were defined as the lower and upper limit for new bone formation. MIMICS 10.01 software (Materialise, Leuven, Belgium) was used to segment the new bone formation in the osteotomy gap from the remaining part of the mandibular body (Figure 2). HU values between 770 and 1000 were defined as new bone; the volume of this region was calculated, and the outcomes in the first and third months were compared.
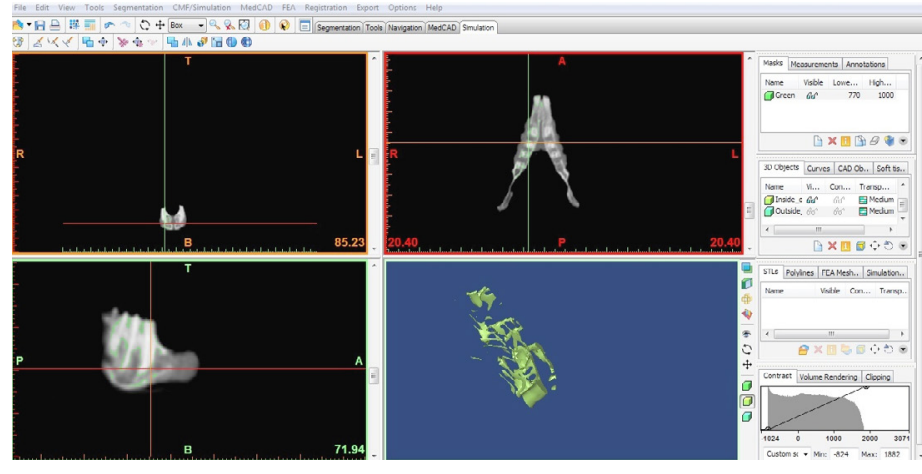

FIGURE 2 - Measurement of volume of newly formed bone in osteotomy gap.

\section{Histomorphometric analysis}

The specimens were stained with hematoxylin-eosin (HE) and Gomori's one-step trichrome stain to observe the new bone formation. The histological images were captured using a light microscope and analyzed with QWin Plus software (Leica ${ }^{\circledR}$, Wetzlar, Germany). The quantity of new bone formation was calculated as the percentage fraction of new bone area.

Inflammation intensity, collagen content, and foreign body reaction were observed in the prepared slices. Foreign body reactions were also determined through the detection of giant cells and granulomatosis reactions.

\section{SEM analysis}

The healing patterns between screws-bone and miniplates-bone and the bone repair of the osteotomy lines were investigated by SEM analysis. The specimens of the SEM group were fixated in $2.5 \%$ gluteraldehyde for four hours, dried with a critical point dryer (Bio-Rad E3000, Hertfordshire, UK) and liquid $\mathrm{CO}_{2}$, and covered with gold particles for SEM (Jeol ${ }^{\circledR}$, Tokyo, Japan) analysis.

\section{Statistical analysis}

All measurements and histological observations were made blindly, with no knowledge of which images belonged to which group. The results were analyzed using the Statistical Package for the Social Sciences (SPSS version 12.0; SPSS, Chicago, IL). The results were tested statistically using Student's t test.

\section{Results}

\section{CT analyses}

Mean newly formed bone volume was $11.2 \mathrm{~mm}^{3}$ at one month postoperative and $34.4 \mathrm{~mm}^{3}$ at the third month; the difference was statistically significant $(p<0.05)$. Thus, the volume of newly formed bone in the osteotomy gap was found to increase over time (Table 1). 
TABLE 1 - Volume of newly formed bone in the osteotomy gap $\left(\mathrm{mm}^{3}\right)$.

\begin{tabular}{cccc}
\hline $\begin{array}{l}\text { New bone } \\
\text { formation }\end{array}$ & Group I & Group II & $\mathrm{p}$ \\
\hline & Mean +/- SD & Mean +/- SD & \\
Histometric & $16.74 / 100+/-$ & $27.31 / 100+/-$ & $<0.005$ \\
& $5.74 \mathrm{~mm}^{3}$ & $5.67 \mathrm{~mm}^{3}$ & \\
CT & $11.2+/-2.3 \mathrm{~mm}^{3}$ & $34.4+/-3.1 \mathrm{~mm}^{3}$ & $<0.005$ \\
\hline
\end{tabular}

\section{Histomorphometric analyses}

Group I: The newly formed bone tissue did not close the gap between bone segments, and intense osteoblast formations were seen in the newly formed bone trabeculae in the osteotomy line. Fibrovascular areas that included intense angiogenesis were observed in the repair areas of the osteotomy line. Adipose cells, fibrotic reaction, connective tissue products, and cartilage tissue were clearly observed, indicating indirect bone repair. The newly formed trabecular bone and the borders of the cartilaginous areas were obviously separated from each other. There was no foreign body reaction, and no cases of giant cell presence were reported (Figure 3).

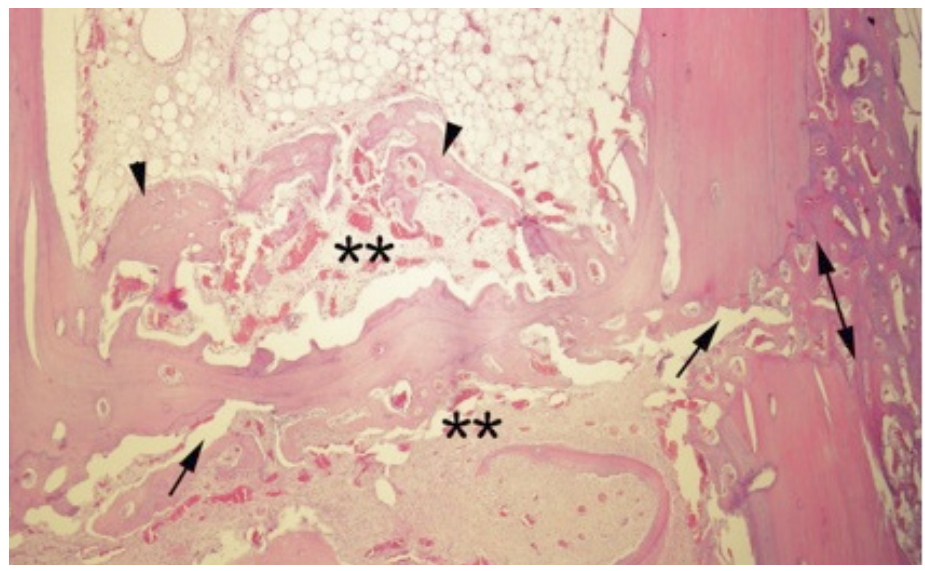

FIGURE 3 - Newly formed bone in fibrovascular tissues (arrow heads), intense vascular products in bone repair area $(* *)$, and newly formed bone tissue (double headed arrow) that did not close the gap between bone segments (arrows).

Group II: Remodeling in the newly formed bone tissue and increasingly dense vascular areas were seen around these structures. Osteocytes were clearly distinguished at the inner parts of the osteoblasts, and remodeling was observed with the activity of osteoclast cells on the newly formed bone tissue. Intense osteoblasts were seen in the newly formed bone trabeculae, and increased bone marrow activities were observed in the bone repair areas (Figure 4).

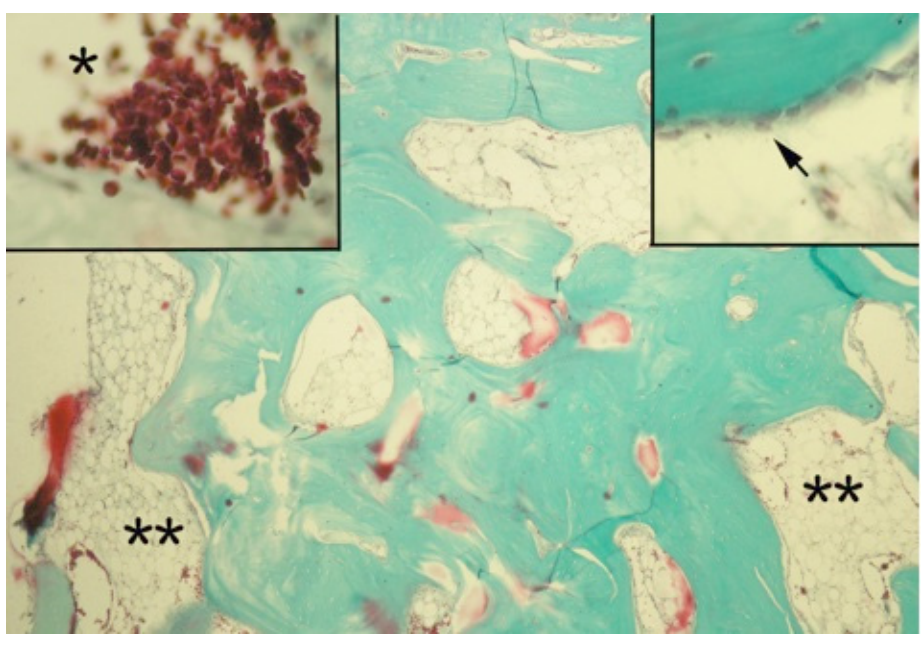

FIGURE 4 - Remodeling was observed with the activity of osteoclast cells on the newly formed bone tissue $(* *)$, Small figures increased bone marrow activity $(*)$, intense osteoblasts (arrow) were seen in the newly formed bone trabeculae.

The results show significant differences between the one month and three months assessments in terms of newly formed bone ratio values $(p<0.05)$. The $\mathrm{CT}$ examinations revealed that there was more new bone formation in the third month (Table 1).

\section{SEM analyses}

Group I: Wide areas were observed between screw-bone tissue and between bone tissue-resorbable screws. Non-union was observed in the bone tissues in the osteotomy line in the area of the bone repair between the screws (Figure 5).

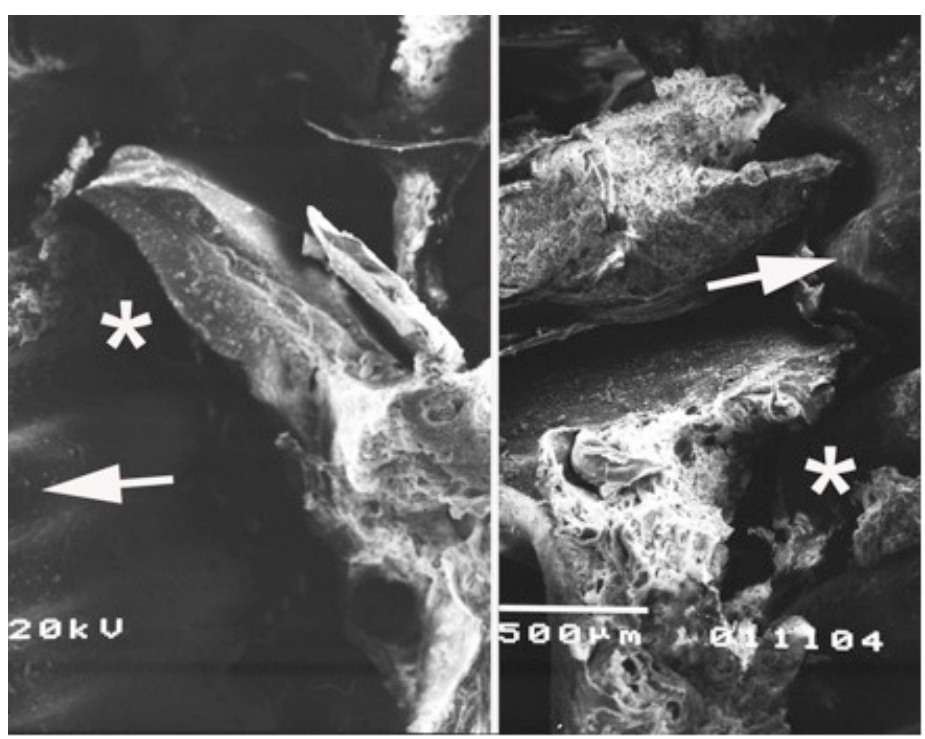

FIGURE 5 - Plates (arrows) and bone tissue (*) between screws. Nonunion was observed in the bone tissues in the osteotomy line. 
Group II: A better adaptation of the bone tissues to the resorbable mini-plate and screws were observed in this group. Total union was observed in the osteotomy line (Figure 6).

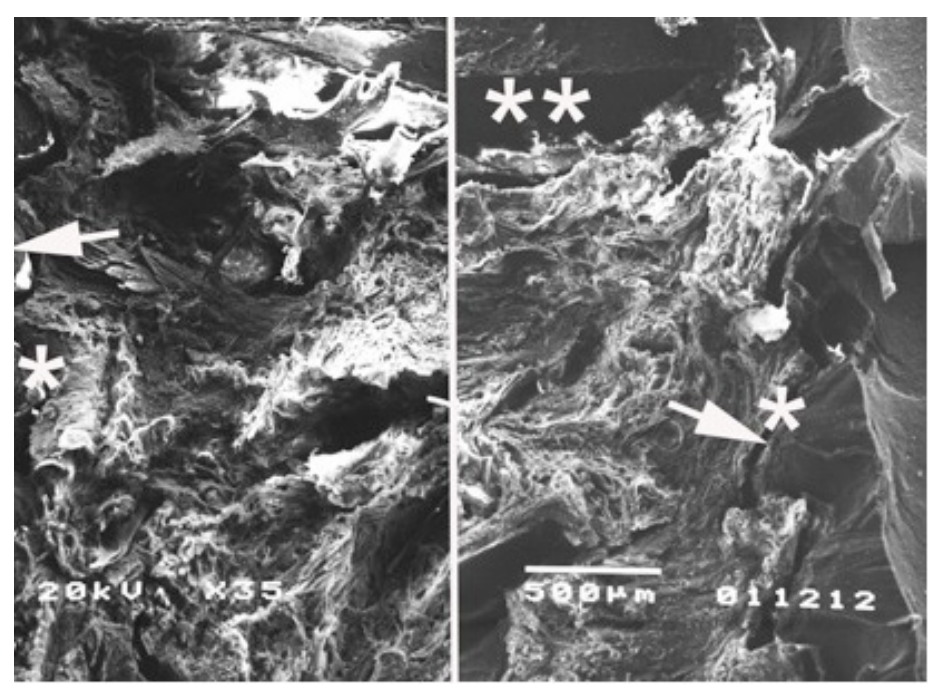

FIGURE 6 - Bone tissue (*) between screws (arrows); plates $(* *)$ between screws (arrows). A better adaptation and total union was observed in the osteotomy line.

\section{Discussion}

Over the past 20 years, there has been an increase in the use of bioresorbable fixation for bone healing and for avoiding a second operation to reduce the operative risk in maxillofacial surgery. Resorbable systems, which provide rigid fixation for bone healing, degrade as the fractured bone regains strength. The interaction among biodegradation, healing of the gap, and bone volume (quantity) in the osteosynthesis region in supporting stability have not been well studied in the current literature. Stability is generally examined in terms of biomechanical stability. Comparisons of metallic plates at particular time-points by means of histological, radiological, and functional outcomes have been presented in several studies. In the current study, to answer the questions of waiting time in resorbable osteosynthesis and to evaluate the progression of osteosynthesis, we compared histological, radiological, and SEM results at one and three months.

In normal bone healing, it is obvious that formation of new bone is expected to increase from day to day; therefore, comparing results after one and three months seems like recapitulating inevitable data. However, the outcomes of resorbable systems have still shown inconsistencies with these expectations in the current literature.
The rabbit model was chosen because of its versatility and the feasibility of the animal based on our previous studies ${ }^{17}$. It is known that the rabbit metabolism is three times faster than that of humans ${ }^{18}$. Thus, the healing periods of four and 12 weeks were chosen for the comparisons because they were long enough to see the effects of the resorbable system on bone formation, such as bone incorporation, resorption of materials, bone remodeling, and amount of bone regeneration.

Biodegradation and inflammatory response to the resorbable screw did not directly contact or interact with the bone healing process. The plate material should be biocompatible with the recipient environment and cause minimal local inflammatory reactions. It is claimed that the materials lose most of their strength between 18 and 36 weeks. There is a $42 \%$ bulk resorption at 40 weeks and complete resorption by two to four years. Choi et al. ${ }^{19}$ reported that resorbable plates may not provide enough vertical stability in the maxillary position due to muscle force after six months. Therefore, healing in the osteotomy gap, is not sufficient to stand functional forces, even after 24 weeks. Resorbable osteosynthesis systems keep their strength for 18 weeks, which is enough for new bone formation. Therefore, to achieve a better bone healing pattern, there is no need to prevent the fixation system from functioning via intermaxillary fixation immediately after surgery.

To date, there is still no consensus regarding the exact time for the fixation system to function. Li et al..$^{20}$ suggested that dental arch stabilization should accompany resorbable mini-plates in order to obtain good stabilization for mandibular fractures in children. Resorbable mini-plates are used to align bone fragments in the proper position and to offer semi-rigid fixation when additional stabilization is required. In our study, bone formation in the osteotomy gap was greater at three months both histologically and radiographically, but we did not compare their resistance to functional forces. However, there was no dental arch stabilization or functional limitation during healing.

No adverse inflammatory foreign body reactions or osteolytic lesions occurred in the present study. In the animal experiments reported by $\mathrm{Luhr}^{21}$ and Niederdellmann et al. ${ }^{22}$, it was concluded that direct bone healing pattern was the pattern that has to be accomplished histologically in the mandible. Contrary to these theoretical expectations, both direct and indirect bone repair patterns were observed in our study. Woven bone, which filled an extensive part of the osteotomy area with small osseous trabeculae and a large quantity of osteocytes of diverse maturity rates, was observed in Group I. No chronic or acute inflammatory reactions were observed in the osteotomy area, consistent with Hochuli- 
Vieira et al. ${ }^{23}$. We found woven bone within the osteotomy line in the presence of endosteal and periosteal callus in the histological evaluation 12 weeks after surgery. We surmised that the resorbable mini-plate acts like a membrane over the osteotomy line and prevents soft tissue invasion through the osteotomy gap.

SEM cannot be regarded as a true quantitative instrument yet, particularly with regard to the contrast and nanoscale level of the resulting image. However, SEM is an ideal observational device for evaluating the adaptation and the interactions among the plate, screws, and bone. Kosaka et al. evaluated fractured biodegradable plates and screws with $\mathrm{SEM}^{24}$. In our study, we evaluated bone-plate interface with SEM. After three months, union of the gap and closer contact between the resorbable plates and the screws were observed.

CT scans have been used to evaluate postoperative stability and the clinical success of resorbable mini-plate osteosynthesis in clinical studies ${ }^{25,26}$. Shapurian et al. ${ }^{16}$ reported that knowledge of the Hounsfield value as a quantitative measurement of bone density can be helpful as a diagnostic tool. Gonzales-Garcia and Monje $\mathrm{e}^{27}$ conducted a study on the reliability of cone-beam computed tomography (CBCT) for evaluating radiographic bone density. They claimed that $\mathrm{CBCT}$ has a strong positive correlation with micro-CT and is a reliable tool for determining bone density. In our study, we compared new bone formation using a standard Hounsfield interval for all samples, and we found a greater volume of new bone formation after three months.

\section{Conclusions}

Resorbable mini-plates for the fixation of mandibular body osteotomy in rabbits accomplished the main goals in the treatment of mandibular osteotomies. The results show significant differences between the one month and three months assessments in the favor of three months in terms of newly formed bone ratio values and newly formed bone volumes.

\section{References}

1. Eppley BL, Reilly M. Degradation characteristics of PLLA-PGA bone fixation devices. J Craniofac Surg. 1997 Mar;8(2):116-20. PMID: 10332278

2. Bell RB, Kindsfater CS. The use of biodegradable plates and screws to stabilize facial fractures. J Oral Maxillofac Surg. 2006 Jan;64(1):31-9. PMID: 16360854.

3. Laughlin RM, Block MS, Wilk R, Malloy RB, Kent JN. Resorbable plates for the fixation of mandibular fractures: a prospective study. J Oral Maxillofac Surg. 2007 Jan;65(1):89-96. PMID: 17174770.

4. Yerit KC, Enislidis G, Schopper C, Turhani D, Wanschitz F, Wagner A, Watzinger F, Ewers R. Fixation of mandibular fractures with biodegradable plates and screws. Oral Surg Oral Med Oral Pathol Oral Radiol Endod. 2002 Sep;94(3):294-300. PMID: 12324781.

5. Ylikontiola L, Sundqvuist K, Sandor GK, Tormala P, Ashammakhi N. Self-reinforced bioresorbable poly-L/DL-lactide [SR-P(L/DL) LA] 70/30 miniplates and miniscrews are reliable for fixation of anterior mandibular fractures: a pilot study. Oral Surg Oral Med Oral Pathol Oral Radiol Endod. 2004 Mar;97(3):312-7. PMID: 15024352.

6. Kallela I, Laine P, Suuronen R, Lindqvist C, Iizuka T. Assessment of material- and technique-related complications following sagittal split osteotomies stabilized by biodegradable polylactide screws. Oral Surg Oral Med Oral Pathol Oral Radiol Endod. 2005 Jan;99(1):4-10. PMID: 15599342.

7. Matthews NS, Khambay BS, Ayoub AF, Koppel D, Wood G. Preliminary assessment of skeletal stability after sagittal split mandibular advancement using a bioresorbable fixation system. $\mathrm{Br}$ J Oral Maxillofac Surg. 2003 Jun;41(3):179-84. PMID: 12804543.

8. Turvey TA, Bell RB, Phillips C, Proffit WR. Self-reinforced biodegradable screw fixation compared with titanium screw fixation in mandibular advancement. J Oral Maxillofac Surg. 2006 Jan ;64(1):40-6. PMID: 16360855.

9. Landes CA, Kriener S. Resorbable plate osteosynthesis of sagittal split osteotomies with major bone movement. Plast Reconstr Surg. 2003 May;111(6):1828-40. PMID: 12711942.

10. Ballon A, Laudemann K, Sader R, Landes CA. Segmental stability of resorbable $\mathrm{P}(\mathrm{L} / \mathrm{DL}) \mathrm{LA}-\mathrm{TMC}$ osteosynthesis versus titanium miniplates in orthognatic surgery. J Craniomaxillofac Surg. 2012 Dec;40(8):e408-14. doi:10.1016/j.jcms.

11. Stockmann P, Bohm H, Driemel O, Muhling J, Pistner H. Resorbable versus titanium osteosynthesis devices in bilateral sagittal split ramus osteotomy of the mandible - the results of a two centre randomised clinical study with an eight-year follow-up. J Craniomaxillofac Surg. 2010 Oct;38(7):522-8. doi: 10.1016/j.jcms.

12. Turvey TA, Proffit WP, Phillips C. Biodegradable fixation for craniomaxillofacial surgery: a 10-year experience involving 761 operations and 745 patients. Int J Oral Maxillofac Surg. 2011 Mar;40(3):244-9. doi: 10.1016/j.ijom.

13. Haers PE, Suuronen R, Lindqvist C, Sailer H. Biodegradable polylactide plates and screws in orthognathic surgery: technical note. J Craniomaxillofac Surg. 1998 Apr;26(2):87-91. PMID: 9617671

14. Sverzut CE, Lucas MA, Sverzut AT, Trivellato AE, Beloti MM, Rosa $\mathrm{AL}$, de Oliveira PT. Bone repair in mandibular body osteotomy after using 2.0 miniplate system--histological and histometric analysis in dogs. Int J Exp Pathol. 2008 Apr;89(2):91-7. doi: 10.1111/j. PMID: 18336526.

15. Sverzut CE, Kato RB, Rosa AL, Trivellato AE, Sverzut AT, da Silveira KM, de Oliveira PT. Comparative study of bone repair in mandibular body osteotomy between metallic and absorbable $2.0 \mathrm{~mm}$ internal fixation systems. Histological and histometric analysis in dogs: a pilot study. Int J Oral Maxillofac Surg. 2012 Nov;41(11):1361-8. doi: 10.1016/j.ijom.

16. Shapurian T, Damoulis PD, Reiser GM, Griffin TJ, Rand WM. Quantitative evaluation of bone density using the Hounsfield index. Int J Oral Maxillofac Implants. 2006 Mar-Apr;21(2):290-7. PMID: 16634501.

17. Atali O, Varol A, Basa S, Ergun C, Hartomacioglu S. Comparison and validation of finite element analysis with a servo-hydraulic testing unit for a biodegradable fixation system in a rabbit model. Int J Oral Maxillofac Surg. 2014 Jan;43(1):32-9. doi: 10.1016/j.ijom.

18. Pelegrine AA, Aloise AC, Zimmermann A, de Mello EOR, Ferreira LM. Repair of critical-size bone defects using bone marrow stromal cells: a histomorphometric study in rabbit calvaria. Part I: Use of 
fresh bone marrow or bone marrow mononuclear fraction. Clin Oral Implants Res. 2014 May;25(5):567-72. doi: 10.1111/clr.

19. Choi JY, Kim JW, Yoo CK, Yun PY, Baek SH, Kim YK. Evaluation of post-surgical relapse in maxillary surgery using resorbable plate. J Craniomaxillofac Surg. 2011 Dec;39(8):578-82. doi: 10.1016/j. jems.

20. Li Z, David O, Li ZB. The use of resorbable plates in association with dental arch stabilization in the treatment of mandibular fractures in children. J Craniomaxillofac Surg. 2014 Jul;42(5):54851. doi: 10.1016/j.jcms.

21. Luhr HG. Compression osteosynthesis in treatment of mandibular fractures--experimental principles and clinical experiences. Dtsch Zahnarztl Z. 1972 Jan;27(1):29-37. PMID: 4500672.

22. Niederdellmann H, Schilli W, Ewers R. [Stable internal fixation of mandibular fractures--an experimental research (author's transl)]. Res Exp Med (Berl). 1974 Feb;162(3):169-74. PMID: 4838115.

23. Hochuli-Vieira E, Cabrini Gabrielli MA, Pereira-Filho VA, Gabrielli MF, Padilha JG. Rigid internal fixation with titanium versus bioresorbable miniplates in the repair of mandibular fractures in rabbits. Int J Oral Maxillofac Surg. 2005 Mar;34(2):167-73. PMID: 15695046.

24. Kosaka M, Uemura F, Tomemori S, Kamiishi H. Scanning electron microscopic observations of 'fractured' biodegradable plates and screws. J Craniomaxillofac Surg. 2003 Feb;31(1):10-4. PMID: 12553920 .

25. Ueki K, Hashiba Y, Marukawa K, Okabe K, Nakagawa K, Alam S, Yamamoto E. Evaluation of bone formation after sagittal split ramus osteotomy with bent plate fixation using computed tomography. J Oral Maxillofac Surg. 2009 May;67(5):1062-8. doi: 10.1016/j.joms.

26. Ueki K, Okabe K, Marukawa K, Mukozawa A, Moroi A, Miyazaki M, Nakagawa K, Yamamoto E. Effect of self-setting alpha-tricalcium phosphate between segments for bone healing and hypoaesthesia in lower lip after sagittal split ramus osteotomy. J Craniomaxillofac Surg. 2012 Jun;40(4):e119-24. doi: 10.1016/j.jcms.

27. Gonzalez-Garcia R, Monje F. The reliability of cone-beam computed tomography to assess bone density at dental implant recipient sites: a histomorphometric analysis by micro-CT. Clin Oral Implants Res. 2013 Aug;24(8):871-9. doi: 10.1111/j.

28. Silva AM, Souza WM, Barnabe Pde A, Koivisto MB, Souza NT. Miniplate 1.5 fixation for the repair of mandibular osteotomies in cats. Acta Cir Bras. 2011 Feb;26(1):31-7. PMID: 21271201.

\author{
Correspondence: \\ Dr. Onur Atali \\ Department of Oral \& Maxillofacial Surgery \\ Faculty of Dentistry, Marmara University \\ Istanbul, Turkey \\ atalionur@gmail.com \\ onur.atali@marmara.edu.tr
}

Received: Feb 22, 2016

Review: Apr 19, 2016

Accepted: May 18, 2016

Conflict of interest: none

Financial source: none

${ }^{1}$ Research performed at Animal Laboratories Unit, Faculty of Medicine, Marmara University, Istanbul, Turkey. 